\title{
Nacimiento y formación de un cronista: Joaquín Edwards Bello y su incorporación al campo literario*
}

\author{
Birth and formation of a chronicler: Joaquín Edwards Bello and \\ his incorporation to the literary field
}

Osvaldo Carvajal Muñoz

\begin{abstract}
RESUMEN
El presente artículo pretende establecer las condiciones que le permitieron a Joaquín Edwards Bello (1887-1968) insertarse y consolidarse en el campo literario chileno de principios del siglo XX. Para ello, siguiendo a Bourdieu, se reconstruye su habitus con el fin de analizar las circunstancias sociales y económicas que llevaron a un joven perteneciente a la oligarquía chilena de principios del siglo XX a convertirse en escritor. Especialmente, se abordará su etapa formativa: la de sus primeras publicaciones tanto periodísticas como literarias. La relación entre la clase social de Edwards Bello y la capital cultural del cambio de siglo, París, es en ese sentido uno de los puntos clave para este estudio. Reconstruir su periplo por las principales capitales europeas permite evidenciar cómo sus primeras estadías en Europa permitieron a Edwards Bello entender el funcionamiento del campo y construir una imagen autorial no solo para ser utilizada en el viejo continente, sino también en Chile a la hora del retorno.
\end{abstract} Palabras clave: Edwards Bello, campo literario, París.

\section{SUMMARY}

This article aims to establish the conditions that allowed Joaquín Keywords: Edwards Bello (1887-1968) to insert and establish himself in the Edwards Bello, Chilean literary world at the beginning of the 20th century. To literary field, Paris. do this, and following in the footsteps of Bourdieu, his habitus

Este artículo surgió en el contexto del proyecto FONDECYT "Revistas culturales latinoamericanas, recorte y globalización de la cultura en la primera mitad del siglo XX", 1190182, a cargo de la Dra. Antonia Viu, de la Universidad Adolfo Ibáñez.

** Chileno. Doctor @ en Literatura con mención en Literatura Chilena e Hispanoamericana en Universidad de Chile. Profesor asistente del Departamento de Artes y Humanidades, Universidad Andrés Bello, Santiago, Chile. osvaldo.carvajal@unab.cl 
is reconstructed in order to analyze the social and economic circumstances that led a young man that belonged to the Chilean oligarchy at the beginning of the 20th century to become a writer. His formative stage will particularly be addressed: that of his first journalistic and literary publications. The relationship between Edwards Bello's social class and Paris, which was the cultural capital at the turn of the century, is one of the key points of this study. Reconstructing his journey through the main European capitals shows how his first stays in Europe allowed Edwards Bello to understand how the literary world works and build an authoritative image not only to be used in Europe, but also in Chile on his return. 


\section{Introducción}

El presente artículo pretende establecer las condiciones que le permitieron a Joaquín Edwards Bello (1887-1968) insertarse y consolidarse en el campo literario chileno de principios del siglo XX. Siguiendo a Bourdieu, reconstruir el habitus de Edwards Bello permitirá establecer "cómo, dadas su procedencia social y las propiedades socialmente constituidas de las que era tributario, pudo ocupar o, en algunos casos, producir las posiciones ya creadas o por crear que un estado determinado del campo literario ofrecía" (Las reglas... 319) y comprender el inicio de su trayectoria, así como la primera concepción de su proyecto creador (Campo de poder... 19). En este sentido, se ofrece el análisis de las circunstancias sociales y económicas que llevaron a un joven perteneciente a la oligarquía chilena de principios del siglo XX a convertirse en escritor; especialmente, aquellas que tuvieron que ver con su formación cultural primera. En dicha perspectiva, es uno de los puntos clave para este estudio la relación entre la clase social de Edwards Bello y la capital cultural del cambio de siglo, París. No hace falta decir que la ciudad luz, a fines del siglo XIX y principios del XX constituía para la clase alta latinoamericana, una Meca ligada directamente a la obtención de estatus social. El viaje iniciático a París significaba la adscripción al estilo de vida moderno, al esprit de los nuevos tiempos. Reconstruir su periplo por las principales capitales europeas permite evidenciar cómo sus primeras estadías en Europa permitieron a Edwards Bello construir su imagen autorial como lo que Bourdieu llama un escritor burgués desviado (Campo de poder... 117), lo cual habría de servirle no solo en el viejo continente, sino también en su país de origen a la hora del retorno.

\section{Traumas con la institución educativa y primeras publicaciones periódicas}

Los primeros años de Joaquín Edwards Bello transcurrieron en el paso del siglo XIX al XX. Esta coyuntura histórica, según Tulio Halperín Dongui, constituye el momento de consolidación de un nuevo orden latinoamericano, pues "iba a ofrecer los capitales que - junto con la ampliación de los mercados consumidores- eran necesarios para una modernización de la economía latinoamericana" (216). Según Bernardo Subercaseaux, esta modernización supuso importantes cambios 
para la aristocracia terrateniente tradicional chilena, que había sido la clase hegemónica desde los tiempos de la Colonia. Entre sus nuevas características, señala "su carácter plutocrático, su cosmopolitismo y opulencia, y la instauración —desde 1891—de un sistema político más adecuado a los intereses del conjunto de la oligarquía (terratenientes, mineros, banqueros, grandes empresarios) y de los partidos que la representan (fundamentalmente liberales, conservadores y nacionales" (307). Por supuesto, estos cambios afectaron directamente los primeros años del autor sobre el que trata este estudio.

Sus dos apellidos hablan de una posición privilegiada: por un lado, estaba emparentado con la poderosa familia Edwards, dedicada a la industria minera y bancaria, que más adelante también será asociada al prestigioso periódico El Mercurio. Por otro lado, desde el punto de vista cultural, era bisnieto de Andrés Bello, según Julio Ramos, el principal ideólogo de la ciudad letrada chilena tras la consecución de la independencia (35). Cabe preguntarse, entonces, hasta qué punto el entorno social de sus primeros años influyó en su entrada al campo intelectual de la época. Para Bourdieu, es este un detalle no menor ya que su visión de la figura del autor exige establecer su relación respecto de las esferas de poder, sobre todo en un campo en plena formación como el chileno:

Los escritores y artistas se encuentran en una situación de dependencia material y de impotencia política respecto de las fracciones dominantes de la burguesía, de la cual provienen y forman parte por sus relaciones familiares y conocimientos o, al menos, por su estilo de vida ... En consecuencia, los escritores y los artistas constituyen, al menos a partir del romanticismo, una fracción dominada de la clase dominante, que en razón de su posición estructuralmente ambigua está necesariamente obligada a mantener una relación ambivalente tanto con las fracciones de la clase dominante (los burgueses), como con las clases dominadas (el pueblo), y a hacerse una imagen ambigua de la propia función social. (Campo de poder... 107-108)

Si hubiera que ubicar a Edwards Bello en el relevante cruce entre campo intelectual y campo de poder según los términos bourdieanos, habría que decir, por su origen, que su figura corresponde a la de los escritores burgueses, quienes "gozan del reconocimiento del público 
burgués (obteniendo de él a veces condiciones de vida casi burguesas) y por ello se sienten autorizados a considerarse portavoces de la propia clase, a la que su obra se dirige directamente" (Campo de poder... 109). Sin embargo, uno de los elementos relevantes en la construcción como autor de Joaquín Edwards Bello es que justamente, cuando comienza a escribir, elige no ser portavoz de su clase, sino todo lo contrario: un ácido crítico que pondrá en riesgo, al menos a ratos, las condiciones de vida que le permiten situarse como un productor privilegiado.

En este sentido, en reiteradas ocasiones, Edwards Bello se refirió a las consecuencias negativas que había tenido en su autoconstrucción como sujeto haber llevado el prestigioso apellido inglés: "Nunca he sido rico de verdad. Vivo más sencillamente que un obrero yanqui. Nunca tuve automóvil. Me llamo Edwards. He conocido, en Chile, las desventajas de llamarme Edwards, no las ventajas. Cuando estuve en el colegio de Inglaterra el apellido Edwards era como aquí Soto. Gran descanso" (Memorias 23). En otro texto, narra lo que le sucedió en el Liceo fiscal de Valparaíso en el que, después de haber sido formado por una nodriza italiana, una institutriz inglesa y haber estudiado la enseñanza primaria en el colegio privado inglés Mc-Kay, un profesor lo acusó públicamente de ser un fils á papá: "Este momento fue como el preludio de la selección a la inversa. Se repetiría más tarde toda mi vida. Era el fruto de la envidia y de la lucha de clases. Me destruyó la confianza" (Memorias 32). Obsérvese, en el mismo sentido, la siguiente reflexión acerca del paso del colegio Mc-Kay al Liceo fiscal de Valparaíso:

Imagine el lector lo que es un liceo chileno: una aglomeración de niños de diversa evolución, de la más disímil condición social y muchas veces de razas diversas. Mi padre nos colocó en el liceo por espíritu democrático, pero yo estimo que fue un error. ... La cuestión social, que ignoramos en casa, se nos presentó en el liceo como cosa viva y viscosa que apenas un velo de disciplina encubría. Extraídos de un hogar meticuloso y exageradamente modesto - donde nos dieron un veinte los domingos - sufrimos la tontería, la ordinariez e ignorancia de los propios educadores que hacían públicamente extensivas sus antipatías de clase, sus majaderías de partidos políticos a los alumnos. Ahí supe -al menos yo por primera vez- que tener tal o cual apellido es como una marca indeleble, 
de tribu, que llevamos por la vida con sus cargas o sus privilegios inherentes ... Ahí el niño pierde la lozanía natural, deja de ser niño, da un salto a la peor madurez con todo su sentido de maldad humana. (Memorias 74)

Hay varios puntos dignos de análisis en las citas precedentes. En primer lugar, ha de notarse el tono martiriológico del discurso de Edwards Bello. Hay un lamento por la determinación de un contexto hostil: la caída del cielo, la expulsión del paraíso que representa el hogar contrasta con la violencia que lo espera en el espacio de la instrucción pública. Un joven de buena familia, criado con todas las comodidades imaginables, es arrojado a un mundo que desconoce. Al respecto, señala Manuel Vicuña que, desde mediados del siglo XIX, la educación estatal en todos los niveles de la enseñanza operaba en contra de la hegemonía cultural de la elite tradicional y que los intelectuales y artistas de clase media comenzaban a predominar en el campo intelectual de la época, "socavando así las bases de la supremacía cultural de la oligarquía, incuestionable hasta ese momento" (41). De este empoderamiento de las capas medias se desprende, entonces, el maltrato que denuncia Edwards Bello. Al describir de esa forma el proceso de "trasplante", lo que está haciendo el autor es oponer dos espacios: el espacio elitista, aristócrata y despolitizado (por tanto totalitario, dependiente de una sola voz de mando, la patriarcal) que representa la casa paterna, frente al liceo democrático, multicultural y cargado ideológicamente que representa la educación estatal. No obstante, será justamente aquel espacio nuevo y caótico el que le abrirá las puertas hacia su primera experiencia escritural pública.

El 17 de marzo de 1901, un Edwards Bello de catorce años aparecía como codirector, junto con Alberto Díaz, del "Periódico Literario, Quincenal" La Juventud. A la vez que estudiante del liceo, Edwards Bello, lector tanto de revistas nacionales (La Lira Chilena, Instantáneas y Luz y sombra) como de publicaciones extranjeras (Barcelona cómica, Madrid Galante, La Lidia), apostaba por convertirse en la competencia de periódicos consolidados como La Unión y El Mercurio de Valparaíso (Memorias 86). Señala Marina Alvarado Cornejo, quien ha estudiado la participación en revistas por parte de autores chilenos de la primera mitad del siglo XX, que esta publicación "tiene conciencia de sí misma en tanto apertura de espacio de los posibles que, a la vez, in- 
gresa a un campo de luchas donde la supervivencia no es sencilla" ("Ni aristócratas..." 33). El primer artículo, titulado "Dos palabras”, explicita los principales lineamientos editoriales de esta "modesta Revista":

no nos mueve otro deseo, ni nos guia [sic] otro ideal que el de ofrecer a la juventud estudiosa un pequeño campo de ensayo. No haremos promesas, que casi siempre resultan vanas; trabajaremos, sí, por despertar en los jóvenes el deseo de saber y distinguirse, en el bellísimo, cuanto difícil arte del bien decir [...] Hoi [sic] entramos a la lid con el alma llena de ilusiones y el corazon [sic] de esperanzas. (1)

En este "pequeño campo de ensayo", financiado por la madre del autor y cuya existencia se extendió por cinco números, eran bienvenidos poemas, crónicas, cuentos y comentarios de diversa índole. Además de lo interesante que resulta por sí sola esta precoz aventura en el periodismo, llama la atención el hecho de que, al referirse en crónicas o entrevistas a este pasquín, Edwards Bello le atribuya, al menos, dos finales distintos a la publicación. El primero, que se encuentra reseñado en el artículo "Mi periódico en 1901" y en "Nuestras lecturas" (ambos contenidos en Memorias), tiene que ver con su padre. Según esta versión, una mañana el padre recogió todos los ejemplares que pudo del tercer número de La Juventud y los quemó en el patio de la casa, frente a los ojos del joven periodista. Esto, pues, a través de una parodia al poema de Espronceda "La Canción del Pirata", en primera página, habían insultado a un abogado y político que su padre conocía $(82,86)$. La otra versión aparece en la crónica "A un cuarto de siglo de mi primera novela", de Recuerdos de un cuarto de siglo, y si bien puede ser compatible con la primera, se verá que tiene alcances bastante distintos que operan en función de otras intenciones. En este caso, el comienzo del fin de La Juventud tiene que ver con que, al momento de salir el tercer número, Edwards Bello se enfermó. Por ello, el periódico habría quedado en manos de un compañero que se educaba en otro colegio, el de los Padres Franceses. Dado ese contexto, el fatídico número habría sido "arreglado" por un tal padre Mateo, joven poeta peruano que "odiaba" al mentado abogado y que, por ello, habría escrito el paródico ataque. Lo interesante de esta versión, publicada en 1935, es que Edwards Bello no especifica quién ni cómo “cortó los recursos, y paró la publicación". En vez de ello, cuenta que, tras enviarle una carta de reclamo al padre Mateo, notó que "todo Valparaíso" estaba en su 
contra. Para revertir la situación, tuvo que "ponerse bien" con el sacerdote (27).

Ambas versiones son interesantes desde el punto de vista de la construcción autobiográfica que hace el autor en su etapa madura. La imagen de la quema de libros trae asociados los conceptos de idealismo y autoridad contrapuestos; se trata de establecer el mito fundacional de Joaquín Edwards Bello como rebelde, molesto, capaz de incomodar, no solo a su clase, sino a su propia familia. Por otro lado, con la historia del cura Mateo, además de detenerse sobre el poder que determinados sujetos asociados al clero pueden llegar a tener en pequeñas sociedades conservadoras, describe la neumática que se "tramaba" a su alrededor: una suerte de atmósfera conspirativa que lo acorralaba ${ }^{1}$.

No obstante este trágico final, un año después de su debut periodístico en La Juventud, Edwards Bello sorprendería a Valparaíso con otro pasquín: El pololo. Sobre este, declara el autor: "La escandalera fue enorme; tiramos algo más de diez mil ejemplares; sobrepasamos a El Mercurio y La Unión en el interés de los lectores. A la semana pedían un peso por ejemplar" (Recuerdos... 27). En esta ocasión, Edwards Bello sostiene que la publicación no solo ha sido un éxito, sino que ha sobrepasado las ventas de los dos periódicos más importantes de la ciudad. Respecto de su fin, declara que el agente de ventas se quedó con las ganancias y los chantajeó con revelar la identidad de los autores, que hasta entonces era desconocida; de hecho, Edwards Bello escribió con el seudónimo Petit Report. Alvarado Cornejo indica que en este segundo proyecto se observa la autoconciencia que Edwards Bello tiene de sí mismo y de su entorno, "lo que lo lleva a despreciar a la sociedad que margina las aspiraciones literarias y libertarias" pero no evita que, como sujeto-escritor, termine por experimentar cierta "inseguridad moral" (Revistas culturales... 98-99).

$1 \quad$ Más allá de cuál es la versión real de la historia (es posible, claro, que ninguna lo sea), hay antecedentes que confirman que Edwards Bello, teniendo todas las posibilidades para "triunfar" en la alta sociedad de su época, de una u otra manera se las ingeniaba para ubicarse en una posición incómoda, siempre a contracorriente. En sus memorias, el crítico Hernán Díaz Arrieta (Alone) recuerda que, tras publicarse su primera novela, El inútil (1910), lo primero que se cuestionó fue cómo tan "ácida protesta" provenía de un joven que "además de la belleza y el nombre, poseía la fortuna y el talento" (102). 
Probablemente impulsado por estos fracasos (en lo que a réditos obtenidos se refiere) pero también éxitos periodísticos (por lo que toca a la recepción por parte del público), Edwards Bello se atrevió a enviar, más tarde, un "cuento humorístico" a la revista Instantáneas (Memorias 28). De igual modo, en 1903, publicó el cuento "La zapatilla homicida" en la revista Pluma y Lápiz².

\section{El viaje iniciático a Europa}

El próximo hito que vale la pena destacar en esta etapa de adolescencia de Edwards Bello es su relación primera con Europa. Tras una infancia "nutrida de influencias del viejo continente (institutriz inglesa, estudios en el Mac-Kay, trajes de la Casa Francesa, profesores alemanes, exposición a la zarzuela)" (Benadava 155), debido a la enfermedad de su padre, en 1904, la familia decidió hacer un viaje a París. Si bien, en este caso, el viaje tuvo que ver con la búsqueda de una cura para el avanzado cáncer que aquejaba a Joaquín Edwards Garriga, varios autores sostienen que la francofilia y la costumbre de hacer un viaje formativo a Europa constituyen rasgos distintivos de la clase alta chilena de la época (Vicuña 34).

En el contexto de ese primer viaje, el autor leyó en francés, Naná, de Zola: "Apoteosis de la literatura. Iba a dar vueltas entonces por los alrededores del Gran Hotel, en una de cuyas piezas murió Naná, en tanto el público gritaba: ¡A Berlín! ¡A Berlín!”. A su vez, se confiesa lector del fait divers "en la vida y en los diarios": menciona entre sus fuentes Le Journal, Le Figaro, Le Matin, Le Rire, Le Sourire y L'Assiette au beurre (Memorias 87). Habiendo llegado con 17 años, esta primera estadía representará para Edwards Bello un primer acercamiento al estilo de vida del dandi moderno: estuvo de paseo por el Moulin Rouge (Memorias 126), intentó invitar a cenar a la bella Otero (Memorias 172), visitó el Gran Café (Memorias 96) y perdió un manuscrito de novela "a causa del casino" (Memorias 107). No obstante esta vida de aventuras, una de las últimas decisiones de su padre, seguramente orientada por la misma razón que lo había llevado a inscribir a sus hijos en el Liceo fis-

2 Este apareció el 26 de abril, en el número 123, año III. Llama la atención que en ninguna de las crónicas en que revisa su trayectoria como autor, Edwards Bello nombre ni la colaboración ni la revista. 
cal de Valparaíso, fue que Edwards Bello ingresara a una escuela anglofrancesa llamada Ecole de l'entente. Estuvo cuatros meses ahí y, tras la muerte del padre, en 1905, sería enviado a estudiar a Londres, donde su tío Federico Gana se haría cargo de él. Por los registros que han quedado de los recibos en que Edwards Bello detalla en qué ocupaba el dinero, Benadava sugiere que "continuaba en Inglaterra la carrera de dandi precoz que había iniciado en París" (103) ${ }^{3}$.

Todo apunta a que esta primera estadía del autor en Europa (Francia, España y Londres) sirvió más que nada para nutrir su enciclopedia, tanto literaria como periodística, y respirar los aires modernos de las metrópolis europeas.

\section{El regreso a Chile: instalación de la neumática y una precoz corresponsalía internacional}

En 1906, Edwards Bello deja sus estudios en Londres: la familia regresa a Chile, pues el terremoto que había azotado a la quinta región del país tuvo su epicentro en Valparaíso, su hogar (Memorias 54). Las alusiones que existen al momento de su llegada al país son múltiples, pero todas coinciden en algo: el pequeño y travieso muchacho había cambiado y este cambio generaba en su entorno reacciones que, a decir del autor, habrían de marcarlo para siempre. Son dos los choques culturales que tiene Edwards Bello a su regreso: el primero, en su ciudad natal, Valparaíso; el segundo, al ir a instalarse a Santiago, la cada vez más moderna capital del país. Con respecto a su arribo a la ciudad natal, señala en "Tierra de temblores", contenida en Crónicas. Valparaíso-Madrid (1924):

me dolió encontrar una indiferencia grande en la gente, en la poca gente que encontré de mi época.

Fue una impresión amarga. Todos ellos me hablaron y me consideraron sin sorpresa ni curiosidad, como si viniese del pueblo de al lado, de Limache o Peñablanca ... Yo no llevaba ningún invento nuevo, ni dinero para especular. No llevaba más que una ilumina-

3 En Memorias, páginas 111 y 112, hay reproducciones facsimilares de dos documentos de este tipo. 
ción interior de intensa vida nueva. Un frío, ¿cómo le va? Fue una lluvia cruel en los fuegos vivos de mi memoria. (105)

Desde el primer momento, el autor se siente incomprendido. Toda aquella ilusión melancólica sentida "por allá en alguna noche de bohemia decepcionante" se transforma en una decepción aún más amarga (106). Para completar la imagen de desolación espiritual, agrega en el siguiente párrafo:

Algunos amigos de la infancia pasan cerca de mí, sin conocerme; están cambiados ... me reconocen, pero me miran de reojo; yo comprendo ese sentimiento; sé por qué han adquirido esa fisonomía de perros corridos ... Ellos me dan, más que nada, la medida del tiempo, el tiempo que ha pasado, lo que yo mismo he cambiado y envejecido. Siento más atracción y simpatía por los que naufragaron ... el fracaso los ha hecho tímidos. Pienso en cómo los ha defraudado la vida. (106)

Hay, en este último párrafo, una reflexión especular desde el otro, representado por sus viejos conocidos: el recién llegado de la metrópolis europea ve el cambio operado en los otros, los que se han quedado. Cuatro años han bastado para envejecerlo y, desde esa posición de sabiduría, compadece a quienes no han tenido su misma suerte: voluntariamente o no, Edwards Bello dibuja un cuadro en que se lee entre líneas que se considera en un estado superior al de sus pares porteños. Todo lo contrario se leerá al momento en que narre su recepción por parte de la sociedad santiaguina.

En "A un cuarto de siglo de mi primera novela", crónica contenida en Recuerdos de un cuarto de siglo, señala el autor que llegó a Chile "enguantado en suaves casimires de Debacker, saturado de la primera petulancia volteriana y zolesca". Identificándose como "forastero" en los principales paseos de Santiago, recuerda que, "en el centro u ombligo de la ciudad provinciana", "las miradas fusilaban a cualquier que no hubiera nacido y vivido en la cultura mapochina, domiciliado entre Matucana y Mosqueto" (28). Presenta Edwards Bello una imagen contrapuesta a la del provinciano de Jotabeche, la estampa del muchacho de región, atónito y sin saber actuar ante la novedad y modernidad urbanas: él representa esos conceptos, tanto en su vestimenta como en sus modos de mostrarse en el espacio público. En "Cómo me hice escritor I", se presenta a sí mismo, a su regreso, "muy elegante; medio ton- 
to, volteriano, displicente; loco lindo, al decir de los argentinos" ( $M e$ morias 88). El efecto que esta pose cínica y pretenciosa habrá de tener en la recepción del autor trae asociada una palabra que, más arriba, se dejó pasar sin explicación pues cobra un sentido aún más rico tras la presentación de las siguientes citas: "Lejos de tomarme en chunga, la sociedad se encoge. Neumática. Algo de envidia y mala intención en los amigos, que van a tomarme frases hechas y corbatas de Charvet. Vacío. Un baile social estupendo. Medio Santiago está invitado, menos yo. Nadie me da un consejo; me censuran". Tras enunciar que, en esta situación de aislamiento, no visita siquiera a sus únicos parientes cercanos por una timidez que es mezcla de audacia y soberbia, sentencia que esa característica "La toman por otra cosa. La neumática viscosa crece a mi alrededor" ${ }^{4}$. Edwards Bello considera que en torno a él hay una cierta atmósfera hostil, amenazante, la neumática. No es el primer momento en que la siente: ya se veía en la sensación de paranoia que describía tras el episodio del cura Mateo, asociado a la publicación de La Juventud. En este sentido, si se lee desde el punto de vista de la reelaboración autobiográfica, lo que hay en esta escritura memorial es la justificación de una actitud a la defensiva, una apología al retraimiento en que vivía el autor en sus días de madurez. Otra operación de interés para este estudio tiene lugar en la última crónica citada. Edwards Bello, exactamente a continuación de donde termina la última cita, dice: "Guardo mi pasión. Como en una caldera, esos desafíos hierven, esos desprecios fermentan en mi alma. Queda un camino solo, para irrumpir: las letras. Recuerdo que a los once años saqué El Pololo, periódico satírico. A los trece, La Juventud... Está echada la suerte. Escribo una novela" (Memorias 88). En primer lugar, hay que reparar en que la "vocación" literaria, el llamado, se representa como respuesta al rechazo social. Ya se han presentado tres imágenes que apuntan en esa dirección: la simbólica quema de La Juventud por parte del padre; el rechazo social que le produjo la enemistad con el sacerdote peruano; y, por último, el desprecio que le acarreó un regreso triunfal desde la cuna de la cultura moderna. Estas tres circunstancias apuntan hacia los mismos conceptos: incomprensión y aislamiento. La neumática, como metáfora, es la atmósfera que lo aísla de aquellos que no lo comprenden y, por tanto, es la causante de que tome el solitario camino

$4 \quad$ La negrita es del original. Será así en todas las citas de Memorias. 
de las letras ${ }^{5}$. Cabe considerar, en este sentido, que para Bourdieu la vocación no es más que un sistema de disposiciones a través de las cuales la relación objetiva del productor cultural con el mercado de trabajo se traduce en una carrera o trayectoria y, en este escenario, serían factores secundarios (como las mentadas experiencias de rechazo y discriminación) los que generarían "un tipo particular de desviación respecto del haz de trayectorias características de la clase" (Campo de poder... 118).

En este sentido, cabría reubicar entonces a Edwards Bello entre los escritores que el sociólogo francés llama burgueses desviados, aquellos que rompen con las normas y los valores de la propia clase estando dispuestos a responder a las expectativas del público burgués pero, a la vez, también a mostrarse incapaces de satisfacerlo (Campo de poder... 117). Su desviación, en este caso, sería explicada por los constantes vacíos sociales que experimenta el autor y que lo llevarán a aislarse en la trinchera de la escritura y, desde allí, devolver los golpes que tanto resiente. Respecto de esta época, en una entrevista de 1926, Edwards Bello declaró:

De regreso de aquel viaje [1904-1906], empobrecido por una vida que excedía en su fastuosidad a mis recursos pecuniarios de entonces, me instalé aquí en Santiago como modesto pensionista del hotel Fornos. Para disolver mis horas de hastío y también para desahogar los rencores que me había creado la hostilidad social con que fui recibido a mi regreso de Europa, escribí El inútil, que, aunque estaba indeciso de su valor literario, me llenó de orgullo ${ }^{6}$. (García-Huidobro 70)

5 En esta crónica, “Cómo me hice escritor I", Edwards Bello manipula los hechos en dos sentidos. Ya se ha expuesto que El Pololo fue publicado un año después que La Juventud, cuando Edwards Bello tenía quince años; no once, como señala en la mentada crónica. Habría una operación de adelanto de las fechas en un afán de resaltar la precocidad de la lucidez que el joven autor habría tenido respecto del campo cultural de su época. Por lo demás, por cómo estructura sus párrafos, poniendo inmediatamente después del regreso de Europa la mención de los periódicos juveniles, da la impresión de que los hechos suceden de la siguiente manera: viaje a Europa, regreso, neumática, epifanía, El Pololo, La Juventud, El inútil. No obstante, se ha dejado en claro que no es así.

6 Esta entrevista apareció el 2 de enero de 1926 en Zig-Zag y fue hecha por Ramón Ricardo Bravo. 
En otra ocasión, refiriéndose a las circunstancias de escritura de su primera novela, señala: "Yo había escrito El Inútil en diversas carillas de papeles al azar; sin corregir. Hoy corrijo. Antes no. El Inútil viajó en una maleta de hotel en hotel" Agrega que, por no pagar la renta, había quedado la maleta con el manuscrito "en rehenes". Tras acudir a pagar la cuenta y conseguir la liberación de su equipaje, cuenta que partió "a otro hotel en la Alameda" (Memorias 107). Esta circunstancia vital "adversa" difícilmente se dio por necesidad económica. Sin embargo, encontramos a un Edwards Bello que se aísla, que se viene a la capital y que vive en "el miserable Hotel Fornos" pudiendo haberse hospedado en las casas de sus mismos parientes o en hoteles de mayor prestigio. Cuesta dudar, en ese caso específico, de la palabra de Edwards Bello, pues su primo, Andrés Balmaceda Bello, confirma la historia y, de hecho, probablemente, lo encuentra en un momento posterior al recién revisado: "Joaquín estaba viviendo en un hotelito del portal Edwards, de cuya existencia no tenía noticias". El portal Edwards, inaugurado en 1901, era un complejo hotelero y comercial que, ubicado en la Alameda, albergaba desde el lujoso Hotel Royal hasta "hotelitos" como aquel en el que se encontraron los primos en 1908:

el aspecto del hotel y de la pieza eran algo sórdido, pero no me interesaba. Joaquín dormía a pierna suelta en una cama de fierro, bastante desordenada. Tuve que despertarlo. Fue sin duda una sorpresa, y en cierto modo, agradable, porque me confesó que hacía más de un mes que no veía a nadie. Solo a algunos amigotes de esos que salen de las tabernas de otro medio. $(28)^{7}$

Poco queda del protodandi que había recorrido las principales ciudades del viejo continente. Edwards Bello le cuenta que está escribiendo una novela sobre temas y personajes de la sociedad santiaguina. Cita Balmaceda a su primo: “ $¿$ No encuentras tú aberrante que vivamos siempre en este engaño? ¿Que la sociedad, para darnos su visto bueno, nos haga pasar y repasar por las horcas caudinas de sus convenciones

$7 \quad$ En un artículo recopilado en Bajo el polvo de los años, titulado “Joaquín Edwards Bello (época de juventud)", publicado en El Mercurio el 10 de marzo de 1968, Balmaceda retrató de otra manera este encuentro: "lo recuerdo en ese entonces cuando escribía El Inútil en la pieza del hotel del Portal Edwards, encerrado como un fugitivo, en medio de ropas y papeles que andaban por el suelo, escribiendo con la luz de la lámpara, porque aún no había abierto las ventanas, mientras en la bandeja del desayuno abandonado debajo de la cama las moscas saciaban su apetito" (134). 
y mistificaciones? Te voy a leer un párrafo de mi libro para que veas si tengo razón" (28). Aparece, nuevamente, un Edwards Bello que se rebela ante las convenciones de la clase que lo vio nacer y se resiste a adaptarse a los modelos de conducta tradicionales. La neumática, se podría decir, parece haber tomado control de los actos del autor en el sentido de que sus movimientos están definidos por oposición a las convenciones.

Es arduo encontrar mayores antecedentes en torno a los pasos de Edwards Bello hasta la publicación de El inútil. Hasta el momento, los ejercicios escriturales publicados del autor han sido dos periódicos satíricos en Valparaíso y dos cuentos en revistas santiaguinas. Sin embargo, he aquí un elemento hasta hoy desconocido y sorprendente.

El 19 de agosto de 1909, en El Diario de Alicante, apareció en primera página un artículo titulado "Una idea", firmado por "Joaquín Edwards Bello (CHILENO)”. Cuatro días después, en La Región Extremeña, de Bajadoz, el mismo artículo. El texto propone "una idea" enviada "sin pretensiones", "por si acaso puede servir de algo", por un firmante que se declara "hijo amante y admirador de la madre patria". La propuesta de Edwards Bello tiene que ver con la guerra de Melilla, la cual España estaba librando contra las cabilas rifeñas desde julio de ese año. El chileno abre su artículo con una frase que autoriza la opinión que va a manifestar a continuación: "A todos los que siguen con interés los diversos incidentes de la campaña de Melilla ha llamado grandemente la atención el número enorme de oficiales muertos por parte del ejército español". Edwards Bello, desde Chile, manifiesta que, al igual como cuando era niño y adolescente, parte de sus lecturas está constituida por la prensa que cubre las contingencias de la situación europea. Esta necesidad de autorización será reforzada por uno de los que, en el futuro, será de los principales recursos utilizados en la elaboración de sus crónicas, la cita; en este caso, a periódicos europeos: "Y así vimos que después del terrible combate del día 27 de julio, los diarios de París, Londres y Berlín reprodujeron telegramas enviados por agencias poco escrupulosas, en los que se daba á [sic] ese hecho de armas toda la extensión de un desastre". Una vez demostrada la pertinencia de su voz en el caso, el autor pasa a esbozar una explicación del desastre que quiere analizar. Lo que llama la atención de Edwards Bello es la inmensa cantidad de bajas, 
en el contexto de la mencionada batalla del 27 de julio, de oficiales del ejército español: casi todos habían muerto en combate. Esto lo atribuye a que son "fácilmente reconocibles por el uniforme y por llevar la espada en vez del fusil". Recurriendo a su enciclopedia, y con el fin de encaminarse hacia su propuesta para solucionar el problema, Edwards Bello expone el caso de la estrategia utilizada por las tropas rusas en la Guerra de Oriente (1877-1878) y la reciente reforma militar que habían hecho los franceses: respectivamente, la autorización a los oficiales para usar en batalla el mismo fusil y uniforme que los soldados y la supresión de los tambores de guerra, "que tantas veces habían llamado á [sic] sus soldados en momentos de gloria y cuyo recuerdo iba unido al de las mejores tradiciones". Llama la atención que este Edwards Bello de veintiún años, con un pasado escritural ligado a un humor ácido y al escándalo provocador, haga el ejercicio de leer la contingencia, no de su país, sino de una nación extranjera desde un punto de vista histórico y, además, que haga el intento (con éxito, en este caso) de ser parte de su discusión. Pareciera que la España de 1906, de vacaciones aristocráticas en San Sebastián y aventuras de casino, dejó algo más que simple nostalgia bohemia en el joven escritor ${ }^{8}$. En este texto, están presentes, germinalmente, varias de las características que moldearán el estilo de escritura de sus crónicas futuras: las citas a la autoridad; la utilización de fuentes y hechos históricos ofrecidos como ejemplos para comparar y contrastar con el tema que se analiza; el tono epistolar que, muchas veces, adquirían sus reflexiones; $y$, finalmente, sus constantes juicios generalizadores (Carvajal, "El pájaro verde..." 442).

\section{El inútil: debut controversial como novelista}

El hito que sigue en la carrera de Edwards Bello es la publicación de El inútil en 1910. Algo se ha adelantado ya sobre las circunstancias en las cuales fue escrita la novela. Más que entrar en un análisis del texto, lo que se pretende aquí es documentar los hechos previos y posteriores que habrían de ser determinantes en la carrera del futuro cronista.

8 Sin embargo, esta aparición en la prensa española, en esa época, es un fenómeno aislado; no se ha encontrado más material de esa índole en las pesquisas realizadas en la investigación correspondiente a este trabajo. 
En este sentido, cabe recoger la anécdota de un encuentro del autor con un viejo amigo, quien sería el responsable de la publicación de la novela: "En agosto de 1910, me encontré con Arturo Wittig Iñiguez. Este amigo había sido mi testigo en un duelo que tuve dos años antes. Me expresó que trabajaba en la Imprenta Universo. Hablamos de mi novelita. Me pidió los manuscritos y El Inútil apareció en los primeros días de septiembre del año del Centenario, en 1910" (Memorias 107). Es digna de reflexión la facilidad que el conocimiento de determinado personaje, perteneciente a su misma clase social, otorga al proceso de publicación.

Sobre la recepción de $E l$ inútil, es necesario considerar que gran parte del mito que se creó en torno a esa primera obra tuvo que ver con la performance realizada por Edwards Bello tras su publicación. Recuerda Andrés Balmaceda:

A su autor no se le encontraba en Santiago ni en Valparaíso ni en ninguna parte. Andaban rumores que decían muchas cosas, pero lo cierto es que él sabía que iba a herir a su propio ambiente y que era prudente escapar a los pelambres, a los respingos y a los desagrados. El inútil fue, pues, su primera obra. Nacida de los primeros choques de sus teorías y reflexiones con la realidad de la vida. Si bien el éxito de este libro, por lo menos en la parte literaria, no alcanzó altos niveles, circuló profusamente en todos los grupos literarios y sociales, despertando interés, curiosidad, aplausos entusiastas y críticas acerbas. Estuvo bien que se hubiera ausentado del país; así las cosas pasaron en calma y la sangre no llegó al río; pero la sociedad se sintió ofendida. "Jamás, decían, se ha publicado un panfleto más inmoral y más atrevido, y la propia familia es la más enrostrada. La mentira, la calumnia y la insidia son la sustancia con que se llenan sus páginas". (29)

Tanto revuelo tenía que ver con el hecho de que la obra, en apariencia, estaba escrita en clave, es decir, los personajes y sus conflictos eran representaciones de personalidades de la alta sociedad santiaguina. Por su parte, en "Memorias de 'El inútil", Edwards Bello cuenta: "A los diez días de haber publicado El inútil me sentí héroe de la más diabólica celebridad. La mitad del público me repelía. La otra mitad me aplaudía. No he vivido nunca para la opinión pública, pero fui sensible al vacío social que me hicieron entonces. Era inocente. No pensé en 
clave, pero me traicionó la imaginación" (Memorias 109). Agrega que, en ese contexto, debido a la popularidad de la obra, fue acogido un día en la "bulliciosa mesa de bohemios" de un restorán de la capital: "Comprendí en el acto que había perdido mi otra identidad". Junto al reconocimiento de sus pares escritores, tal como señala Balmaceda en sus memorias, se encontraba también el desprecio de aquellos miembros de su clase que lo evitaban y le quitaban el saludo. Ahora bien, la explicación de la desaparición a la que aludía Balmaceda la ofrece en esta misma crónica el autor: "Días inolvidables siguieron a medida que yo era más indeseable. Me refugié en cierta casa de mal vivir en la calle de Borja, final de Santiago" (110). En "La obscenidad de la literatura", de 1954, agrega:

conocí el prostíbulo de Ema Laínez, en la calle Borja N. ${ }^{\circ} 227$, en el que anduve perdido después de publicar El inútil en 1910 ... La tortura espiritual producida en mí por la publicación de El inútil me hizo tomar el camino del refugio, no en una Legación extranjera, como hacen los políticos, sino en una casa non sancta. En el fondo, me escapaba de mí mismo. (Recuerdos de... 88)

He aquí un punto clave, pues si se consideran las palabras del autor sobre El inútil en la ya citada entrevista de 1926, en que señala que esa novela fue escrita para disolver sus horas de hastío "y también para desahogar los rencores que me había creado la hostilidad social con que fui recibido a mi regreso de Europa" (García-Huidobro 70), hay una tremenda contradicción en su actuar: partiendo del rechazo que provoca su regreso a Chile, Edwards Bello devuelve el golpe a la alta sociedad hiriéndola donde más le duele, su honra. ¿Cómo pudo esperar no salir herido de un lance de este tipo? He ahí el desvío de la trayectoria cómoda y tranquila que le hubiera significado ser un escritor de y para su clase.

Como adelantaba Balmaceda, para escapar nuevamente de la neumática, Edwards Bello emprenderá un viaje: primero, a Buenos Aires; luego, a Río de Janeiro. Declara el autor que entró en Río "sucio y con poco dinero" (Memorias 110), lo cual le sugirió una idea que, hasta el momento, nunca había pasado por su cabeza: trabajaría para subsistir. Gracias a su buen manejo del inglés y el francés, consiguió una ubicación como corredor en un hotel. Sin embargo, este "nuevo principio" no estuvo ausente de complicaciones: empezaron a aparecer pasajeros 
chilenos que lo conocían, ante lo cual no hallaba mejores soluciones que esconderse, cambiar el acento y ocultar su rostro. Hasta que, un día, apareció un diplomático chileno que lo descubrió: "Al oír mi nombre completo, con la pronunciación chilena, mi corazón dio vueltas. Me vencía la facilidad, la buena posición. Esa facilidad para vivir que nos hace flojos y sensuales. Finalizaron mis deseos de trabajar y ganar con las manos" (Memorias 111). A partir de ese momento, el viaje de escape se transformó en un viaje de lujo: hotel, casinos, giros enviados desde Chile. Esta situación le dará la posibilidad de estar muy cerca de la Revolta da Chibata, que estalló el 27 de noviembre de 19109 Sus impresiones y reflexiones al respecto las escribió y publicó a su vuelta a Santiago, en 1911, en el libro Tres meses en Río de Janeiro.

\section{Tres meses en Río de Janeiro: las primeras crónicas}

Esta obra es tremendamente interesante, pues no es una novela, que era lo esperable tras el debut en este género que tuvo el autor un año antes. A medio camino entre diario de viaje, compilación de crónicas, reportaje y ensayo, Tres meses en Río de Janeiro contiene, incluso, una entrevista ${ }^{10}$. Llama la atención un capítulo titulado “En dos líneas", que recoge hechos e impresiones en la breve extensión que su título anuncia, siguiendo la lógica de un mensaje telegráfico. Este recurso, en el contexto de heterogeneidad genérica en que se inserta, pasa desapercibido, pues también hay un capítulo llamado "Notas e impresiones" que contiene breves y fragmentadas reflexiones encabezadas por alguna fecha, a modo de entradas en un diario de viaje. Por otro lado, hay capítulos, como "El juego en Río" o “Chile-Brasil”, que parecen cró-

9 La historiografía le llama Revolta da Chibata ("Revuelta del látigo") a la insurrección de una porción de la marina brasileña que exigía mejoras salariales y el cese de los castigos físicos que comúnmente se aplicaban a los tripulantes que hubieran desobedecido órdenes directas. Comandados por João Candido, "el almirante negro", el 22 de noviembre de 1910, los marinos de los acorazados Minas Gerais y São Paulo tomaron el control de los buques amenazando con bombardear la capital del país si sus demandadas no eran satisfechas por el gobierno. A la brevedad, una ley que suprimía para siempre el uso de la chivata fue dictada, pero muchos de los participantes en la revuelta fueron presos e, incluso, torturados hasta morir. Para más información,véase Mario Maestri, Cisnes Negros: Uma história da Revolta da Chibata, Editora Moderna, coleção polêmica, Porto Alegre, 2000; y, también: Alvaro Pereira do Nascimento, A Ressaca da Marujada Recrutamento e disciplina na Armada Imperial, Rio de Janeiro, Arquivo Nacional, 2001. 10 Cecilia García Huidobro ha incluido este texto en su compilación de entrevistas, con la que se ha trabajado en este estudio, bajo el epígrafe "Una entrevista interesante (en alta mar)", pp. 39-48. 
nicas, pues están construidas en torno a un tema único sobre el cual el autor diserta. Vuelven a aparecer, aquí, las características de la narración periodística y, más importante, la composición del texto no es homogénea desde el punto de vista genérico. Esta misma característica aparecerá en etapas posteriores de la obra de Edwards Bello. Llama la atención el hecho de que la fragmentariedad que se lee entre estos capítulos no es producto de que se hayan reunido en un libro textos que se publicaron individualmente en la prensa periódica, que es una de las características principales de las compilaciones de crónicas ${ }^{11}$. En el caso de Tres meses en Río de Janeiro, Edwards Bello ha decidido conscientemente que esa diversidad salpique los textos que habría de contener su obra. Hay en uno de los capítulos, incluso, un breve diálogo con la crítica sobre su obra anterior:

He pasado todo el día removiendo bilis en interminables excursiones alrededor de... mi cuartito de hotel y me siento triste, casi neurasténico ... He pensado mucho en esos días en que escribí El inútil ... Cuánta razón tuvo Víctor Noir al decirme en bien intencionada crítica, desde las columnas de La Mañana.

'Ojalá el autor dedique sus raras facultades a otra especie de obras más dignas de aplauso y más fáciles de triunfar porque el recuerdo de esta amargará sus éxitos futuros'

Gracias, Víctor Noir, muchas gracias. (150)

El autor se refiere a Enrique Tagle, crítico literario chileno que había sido uno de los pocos que dio un juicio positivo sobre su primera obra (Memorias 108). Aparentemente, la huida no bastó para escapar de las repercusiones de El inútil y el autor toma la decisión de reconocerlo en público.

En sus constantes recuerdos de esa época, Edwards Bello oscilará entre un gran entusiasmo por el potencial del libro y la vergüenza que

11 Por ejemplo, en Sensaciones de París y de Madrid (1900), de Enrique Gómez Carrillo, las crónicas reunidas se presentan como entradas en un diario, justamente, porque el libro está compuesto por artículos que había escrito el guatemalteco como corresponsal para diversos medios: entre ellos, las revistas españolas Madrid cómico y La Vida Literaria. Se encuentran en las Sensaciones fragmentos de cartas, reseñas de obras y notas de viaje que, en algunos casos, han conservado sus títulos, los cuales pasan a ser subtítulos o nombres de capítulos en el libro (Carvajal, "La crónica modernista” 18). 
le provoca la forma en que está escrito. Pero casi siempre es el anuncio de su vocación periodística en esa obra aquello que se destaca en sus comentarios $^{12}$.

Sobre el regreso de Edwards Bello desde Brasil, recuerda Balmaceda: "Joaquín regresaba de Río de Janeiro trayendo trajes nuevos, sambas rítmicas y eróticas, canciones, cuentos y chistes graciosos. Al saber que los Lamarca iban en viaje a Europa, se entusiasmó y partió en compañía de Oscar" (32). Durante esta breve estadía, aprovechó para escribir; al menos en París, pues así lo atestiguan las fechas que aparecen al final de la novela El monstruo (1912) y el cuento "El billete de banco". El mismo autor declaró sobre este viaje en una entrevista: "Ya reflotado con mi nombre... literario, volví nuevamente a Europa en 1912. Allí gasté todo mi patrimonio, cerca de medio millón de pesos, jugando en los grandes casinos. Espejo, aunque mediocre, de esas correrías es $E l$ monstruo" (García-Huidobro 72).

Se suman a su bibliografía ese mismo año la novela La tragedia del Titanic, publicada por Imprenta La Ilustración, y el cuento "Una sola sombra larga..., aparecido el 16 de junio en la revista Musa joven, fundada por Vicente Huidobro y Ángel Cruchaga Santa María. Más tarde este relato, al igual que "El billete de banco", aparecería en la compilación Cuentos de todos los colores (1912), publicada por Imprenta Barcelona. Joaquín Edwards Bello es ya una figura del campo literario nacional: los críticos y sus pares lo conocen y la sociedad lectora de la época ha tenido contacto con sus primeras obras. Dice Balmaceda: "A Joaquín lo veíamos cada vez menos; había entrado en otros grupos más de acuerdo con sus tendencias. Su personalidad literaria se robustecía, pero los comentarios a su respecto no disminuían ni en cantidad ni en acritud" (34).

12 Señala en la crónica "Memorias de ‘El inútil”": “Tres meses en Río de Janeiro es la prueba de fuego de un corresponsal viajero, lo mejor de mi periodismo. Nunca fui otra cosa que cronista viajero" (Memorias 114). En una entrevista publicada en Letras en junio de 1928: "En realidad, mi obra pasada es genial, pero simplemente un borrador. Si yo tomara ahora tales obras como Tres meses en Río de Janeiro o los Cuentos de todos los colores, podría hacer, con esa misma materia, libros de primer orden" (García-Huidobro 98). En otra entrevista, publicada el 18 de mayo de 1954 en Revista Ercilla: "La obra mía que más me gusta es Tres meses en Río de Janeiro, porque es periodística. Me tocó encontrarme en la revolución de Joao Cándido y escribí lo que viví" (García-Huidobro 147). 


\section{El París de la guerra: La cuna de Esmeraldo y la asunción del oficio de escritor}

Ese mismo año, tras haber "gastado su patrimonio" en su estadía anterior, emprende un nuevo viaje a Europa. Según Benadava, "Estaba cansado de su país, de los pelambres, de las intrigas, de los 'tontos graves'. Quería sacudirse de todo eso, olvidar, hacerse olvidar" (152).

Estando en Europa, durante el año 1913, las primeras noticias que se tienen de Edwards Bello son las que da Balmaceda: "Joaquín permanecía en España haciendo relaciones literarias y estudios entre españoles y sud y centro americanos". A su vuelta, llegaba "muy encantado y algo andaluz. Le han publicado artículos importantes en diarios de Madrid y ha hecho amistad con escritores y artistas distinguidos. Tiene en su mente escribir una novela de psicología popular". No debe extrañar esto, pues, según otras declaraciones de Balmaceda, en España ya había logrado entablar "relaciones literarias" (36).

Avanzado el año, tras haberse "desaparecido" Joaquín, su hermana, que también estaba en París por aquellos días, se refiere a sus ausencias de la siguiente forma en una conversación con Andrés Balmaceda Bello: "Por ahí andará, con esos amigotes raros que descubre, literatos, artistas o qué sé yo; gente de vida inquieta y poco recomendable ... usted cree que todos los perdonan; pero no es así, desgraciadamente, hay quienes lo tienen entre ojos, lo descuartizan y lo han borrado de la sociedad" (Balmaceda 65).

De las palabras de su hermana se obtiene la confirmación de lo que Edwards Bello narrara tantas veces recordando el impacto de sus primeras novelas: parte de la alta sociedad lo ha eliminado de sus círculos. Esto se lee en el sentido de que las posibilidades de aspirar a negocios importantes, cargos políticos o matrimonios convenientes se han reducido al mínimo, exclusión que él identifica como la neumática. Se ha dicho que Edwards Bello provoca, durante esta etapa, una y otra vez a su clase social, la desafía: en cuanto se siente herido por ella, vuelve a asestar un golpe más bajo que el anterior. La imagen de su regreso a Santiago vistiendo ropas traídas desde París y su aventura en Río de Janeiro hablan de un sujeto que, teniendo una posición privilegiada en su contexto de nacimiento, se encarga de desestabilizar esa solidez, de ponerla en jaque: ya sea sintiéndose aislado por causa de la envidia 
o intentando trabajar y pasar penurias como lo haría alguien que no tiene los medios suficientes para vivir lujosamente.

Una circunstancia determinante en el modo de pensar de Joaquín Edwards Bello será el estallido de la Primera Guerra Mundial, pues le obligará a desacomodarse y salir de París a huidas para instalarse en Madrid. Desde entonces, entre 1915 y 1920, se le verá en las capitales francesa y española intermitentemente.

En una carta de mayo de 1917, enviada desde París a María Letelier, se evidencia que la relación de Edwards Bello con la ciudad ha sufrido un cambio, pasando a ser más utilitaria que sentimental: "lo que yo aquí vea o aprenda servirá para crearme un pedestal muy alto con el cual sueño noche y día" (Epistolario... 30). En este momento, el autor ya está pensando en su regreso y en elevarse por sobre quienes no han tenido la experiencia europea. Ha cambiado el disfrute sensorial de la ciudad por su estudio. Según Benadava, esto podría ser efecto de la experiencia durante la guerra:

No hay duda que un conflicto de esa naturaleza no se vive impunemente. A Joaquín lo ayudó probablemente a despertar y a madurar; a ingresar de lleno en la edad adulta; a recobrar su identidad; a renunciar a una serie de sueños e ilusiones; a descubrir su sitio en la sociedad chilena y quién sabe si también a interrumpir su carrera de novelista para abrazar la de cronista. (148)

Como se ha dicho, entre 1915 y 1922, Edwards Bello se mueve entre París y Madrid. Pero, como se deja ver en la última carta citada, sus ojos ya miran hacia Chile y su regreso. En marzo de 1917, el autor escribió a su primo Andrés Balmaceda respondiendo a una oferta que le hizo de presentarlo con Eliodoro Yáñez, dueño del periódico La Nación, que había sido fundado ese mismo año. En esa misiva, Edwards Bello expone su concepción sobre lo que un periódico moderno habría de ser y la participación que él podría llegar a tener en el contexto chileno:

temo que mis correspondencias no sean del agrado del público. El público de allá es joven y está todavía en el período de la complicación; le gusta lo ampuloso y estentóreo ... Estimo que los artículos de los diarios deben ser democráticos y sencillos, al alcance de todos los entendimientos, sin rimbombancias ni fililíes. El diario 
moderno es del pueblo, un arma de las masas; debe reflejar ideas populares, ansias nacionales. (Balmaceda 129)

Confiesa, además, que sus referentes para pensar así son la prensa francesa y española. Además, le cuenta al primo que ha enviado algunos artículos para un diario del norte de Chile. Esto quiere decir que, a cinco años de la publicación de sus últimos libros en Santiago, Edwards Bello no ha publicado nada más que artículos periodísticos en España, México y Chile. Declara, además, que su paso por Madrid ha sido productivo para su actividad literaria: "Hice amistad de veras con nuevos escritores, a los cuales, por cierto, no me presenté como literato, sino como simple mortal, sin exhibirles libros, etc.... En pocos meses más verás mi libro que te enviaré con mi afecto de siempre en el cual notarás los progresos de tu primo" (130).

En febrero de 1918, aparece en París La cuna de Esmeraldo. Observaciones y orientaciones americanas. Preludio de una novela chilena. Esta obra fue publicada por la Librería de Paul Rosier, una de las pocas que aceptaba gustosa los ejemplares de literatura en español ${ }^{13}$. Lamentablemente, Edwards Bello no ha dejado en sus crónicas, como solía hacerlo, detalles en torno a la publicación del libro.

13 En ese momento, había cuatro casas editoriales francesas que se dedicaban a la distribución de libros en castellano: Ollendorff, Michaud, Garnier (donde publicaron Enrique Gómez Carrillo, Luis Bonafoux, Rubén Darío y Alfonso Hernández Catá) y Bouret (donde publicaron Amado Nervo, Vargas Vila y Luis Urbina). Sin embargo, gran parte de la producción de estas editoriales se exportaba tanto a España como a Latinoamérica. En 1910, el novelista y dramaturgo Alberto Insúa tuvo la idea de instalarse como el representante en París de la editorial española Renacimiento con el fin de llevar la literatura española contemporánea a un público formado por "los españoles e hispanoamericanos que residen o pasan largas temporadas allí, y también en los profesores y estudiantes que pueden estar interesados en conocer la cultura hispánica" (Fischer 737). En suma, el público objetivo serían todos aquellos latinoamericanos de la clase alta que estaban en medio de su viaje ritual a la capital francesa. Esta pasaría a llamarse, en el otoño de 1912, Librairie Franco-Espagnole, después de que, fracasado su intento de negocio, Insúa decidiera venderle todo su stock a Rosier. Señala Fischer que la ubicación de la librería era propicia para la venta de este tipo de libros, "por estar esta calle cerca del barrio de la Ópera donde viven varios españoles e hispanoamericanos" (740). Añade que Rosier, una vez cambiado el nombre de su librería, no se contentó con vender lo que los demás editores publicaban, sino que editó él mismo algunos volúmenes: es, en ese momento, que debe de haber atravesado la puerta del establecimiento Edwards Bello con su novela bajo el brazo. Fischer declara haber encontrado tan solo tres libros editados por la Librería Rosier entre 1916 y 1920. Entre ellos, no se encuentra La cuna de Esmeraldo. Observaciones y orientaciones americaas. Preludio de una novela chilena. 
Comenzado a escribir en 1912, poco después de que Edwards Bello llegara a Francia, La cuna de Esmeraldo... es, según Salvador Benadava, "un 'bric à brac' (no desprovisto de interés) de escritos de diferente índole y género que anuncian no solo El roto sino, además, parte de la temática que desarrollará ulteriormente en sus crónicas" (132). La metáfora usada es tremendamente acertada, pues la propuesta del libro es transgenérica, carece de cualquier tipo de ordenamiento que le otorgue unidad y ofrece textos que podrían tildarse de incompletos, son promesas de futuros escritos; por lo mismo, son muy valiosos, pues dan la oportunidad de adentrarse en las conceptualizaciones de Edwards Bello distintos temas en su época de juventud y de contrastarlas, además, con el desarrollo que, posteriormente, habrían de tener en su obra.

El libro comienza con "Hablando en americano", una crónica larga o ensayo corto divido en tres partes. En general, aborda la situación de la intelectualidad latinoamericana. Sus tres apartados podrían resumirse, temáticamente, de la siguiente manera: teoría de cómo debiera ser la literatura latinoamericana; comportamiento de los autores latinoamericanos en Europa; surgimiento de las clases medias en las naciones de Latinoamérica. Respecto del camino que debe seguir la literatura indomediterránea, Edwards Bello señala que debe ser "eminentemente criolla, con el naturalismo sano de una raza joven creciendo ante las más risueñas expectativas" (La cuna de... 3) ${ }^{14}$. Considera "apóstoles de la literatura verdadera" a los chilenos Rafael Maluenda, Joaquín Díaz Garcés y Mariano Latorre; los venezolanos Rufino Blanco Fombona y Luis Manuel Urbaneja; el salvadoreño

14 El mismo autor se encarga de explicar el concepto "indomediterráneo" a pie de página: ¿Qué denominación conviene á [sic] nosotros los americanos de habla hispánica ó [sic] lusitana que dé [sic] una idea más clara y completa de nuestra condición de cultura y prosapia? Si yo tuviese el prestigio suficiente me atrevería á [sic] inventar la denominación indo-mediterráneos. Ya no se puede decir America latina: es una pura ilusión que engendra errores. Los paises mismos que nos dieron su lengua tenían ya muy poco del Latió y de Grecia: Arabia y Germania los inundaron; el catolicismo introdujo usos y costumbres de Israel en la civilización Occidental; la raza celta, de origen caótico, florecía en el Norte de Iberia. Digamos pues que nuestros progenitores de Europa eran mediterráneos, expresión vaga si se quiere, pero admitida ya por muchos investigadores ... Indo á [sic] la cabeza indicará la predominancia creciente del vigoroso linaje indígena que nos da el sello nuevo, el aspecto físico y moral sin precedentes en el planeta. Ya el hablar exuberante y aparatoso de Iberia se ha desmayado en nosotros. Es un Tucapel sordo, sin revancha, que se peleó en el espíritu. Somos indo-mediterráneos. (La cuna de... 2). 
Arturo Ambrogi, el peruano Ricardo Palma y el argentino Manuel Ugarte. No es coincidencia que, además de militar en el modernismo (Blanco Fombona, Ugarte, Urbaneja y Ambrogi) o criollismo (en el caso de Latorre, Palma y Maluenda), casi todos los escritores enumerados sean reconocidos por haberse dedicado a la escritura de textos que bordean lo literario pero se insertan en contextos de recepción masiva en que alternan con una dimensión mucho más amplia que la estética: periódicos y revistas. Díaz Garcés y sus crónicas firmadas como Ángel Pino; Ambrogi y Manuel Ugarte, con sus crónicas; Palma y sus tradiciones. En cuanto al género lírico, Edwards Bello subraya la importancia de los principales poetas modernistas, Chocano, Darío y Nervo, así como de los prosistas, Rodó y Gómez Carrillo. Sobre este último y el género que le hizo famoso señala: "Solo nuestra América ha sabido producir croniqueurs con arte bulevardier, galantes y cultos" (La cuna de... 4). Su mensaje es un llamado a escribir desde América para América. No extraña encontrar este texto a modo de prólogo de una serie de cuadros que, en el futuro, formarán parte de una novela de orientación naturalista: El roto, que aparecerá en 1920. Sin embargo, la segunda parte del libro, llamada "algunos capítulos de una novela chilena" no comienza hasta la página 77.

La primera parte, "Hablando en americano" (La cuna de... 1-76), además del texto homónimo, contiene tres crónicas más: "La falta de energías: lo que pasa en mi tierra" (21-58), donde Edwards Bello hace una ácida y demoledora crítica a la clase alta chilena y sudamericana en general; "Germinal suramericano" (59-63), el retrato de Jorge Newberry, un aviador y sportsman argentino que llama la atención del autor por el positivo efecto que ha tenido en la juventud de su país; y, finalmente, “Chile en el mar. 1829 - 1879 - 1891", en la cual aborda la importancia estratégica, geopolíticamente hablando, que debería tener el mar en la cultura chilena ${ }^{15}$.

15 Resulta interesante la mención que hace Edwards, en esta crónica, de su novela de 1911 al momento de referirse al escenario que propició el alzamiento de la armada brasileña: "En Tres meses en Río yo señalé esa democracia blanda que da la mano al tendero, que dice Excelencia al negro y que prepara el maximalismo mulato de Joao Cándido. Roosevelt alabó lo que en su tierra habría condenado" (65). Desarrolla la idea para, luego, preguntarse: “ ¿No son parecidas las observaciones que hice en Río cinco años atrás?" (66). 
El título de la segunda parte habla por sí solo. "Algunos capítulos de una novela chilena (La cuna de... 77-190) ofrece la "médula espinal" de la novela El roto:

En los primeros capítulos de esta novela, escritos en 1912, como consta á [sic] muchos de mis amigos chilenos á [sic] quienes leí algunos trozos, trato extensamente de los abusos policiales que el gran público ha venido á [sic] conocer hace solo dos años por las revelaciones de un diario ... Tanta novedad tenían esos capítulos en 1912 que más de una persona prudente, y quizás incrédula, me dijo que sería temeridad darlos á [sic] luz, porque caería sobre mí el furor del entonces semi-dios policial, respetado y utilizado por nuestros dirigentes. (77)

Uno de esos cautos consejeros fue el primo Andrés Balmaceda, quien conversó en París con el autor acerca de la novela que estaba preparando. Todo indica que estas escenas fueron compuestas en 1912, como señala Edwards Bello. Sin embargo, en otros capítulos del libro, se hacen alusiones a fechas posteriores, al estallido de la Guerra y eventos de 1916. En esta segunda parte, Edwards Bello introduce a los principales personajes y conflictos de la que será su novela más exitosa ${ }^{16}$.

La tercera parte se titula "La experiencia de los viajes" y está compuesta por cuatro crónicas largas y un cuento. Se inicia con "Noción confusa que de la América indomediterránea tienen los europeos" (La cuna de... 191-204), que habla de la nula presencia que tienen las literaturas latinoamericanas en Europa y que anuncia, esperanzada, el día próximo en que el viejo continente, devastado por la guerra, tendrá que volverse hacia América. A continuación, en "La Pampa y la Montaña" (205-218), Edwards Bello intenta explicar la determinación que han ejercido las disímiles geografías de Chile y Argentina sobre el carácter de sus pueblos. En "La alegría de las criadas" (219-230), el autor invita al lector a seguirlo en un viaje a la Fuente de la Teja, en los arrabales de Madrid, donde van de paseo las criadas madrileñas los días domingo: es una apología a la mujer de trabajo española, a la

16 Los títulos de los capítulos son: "El hijo de una tocadora" (80-108), "El garitero y el político prevaricador” (109-144), “La iniciación de María” (145-164), "La vocación de María" (165-176), "El amigo del rotito" (177-190). 
que postula como el ideal de compañera para cualquier hombre y la contrasta con la chilena para finalizar haciendo una reflexión sobre la diferencia de clases en Latinoamérica. En "Seudo-letrados" (231242), critica a los "señoritos cursis americanos" que adhieren a las últimas modas literarias produciendo obras "mediocres" y "sin espinazo". Dedica largos párrafos a criticar la costumbre del artista recién llegado a París de acercarse a literatos de renombre para elevarse sobre los demás colgándose de la fama ajena. Finalmente, el cuento "Amores de arrabal (Aventura de un americano sencillo)" (242-248) ofrece la historia de un joven escritor latinoamericano de clase alta que vive en una pensión humilde y tiene amores con la hija de la casera: un primer boceto de lo que, años más tarde, será la novela $E l$ chileno en Madrid (1928).

Uno de los aspectos más llamativos de la escritura de las crónicas que acompañan a las primeras escenas de El roto en este libro son los deícticos que el autor usa al comentar los temas que aborda. Hay un constante "nosotros" que refleja su inclusión como sujeto latinoamericano y chileno y a la vez un "aquí", representado por París, que es el lugar desde el cual escribe. Aunque podría parecer contradictorio o inconsistente, hay que recordar que la Librería Rosier, que editó y publicó la obra, estaba dirigida específicamente al público latinoamericano residente en la capital francesa. Edwards Bello, sabiendo esto, llega incluso a usar explícitamente el vocativo "lectores chilenos" $(223)^{17}$.

Ya se ha dicho que, como conjunto, estos textos son un llamado a una concepción latinoamericanista de la escritura en clave de diagnóstico: Edwards Bello ofrece, desde la periferia de la ciudad-luz, desde el margen que supone ser latinoamericano en Francia, la visión que (no) tienen los europeos de la intelectualidad del continente

17 Se suma a esto que, a lo largo del libro, en las crónicas, se encuentran varios pies de página que explican nombres y conceptos que aquel que no ha estado en París o no tiene la enciclopedia suficiente podría no entender. Por ejemplo, el verbo "flaner", que Edwards Bello define como "Pasearse por las calles con el ánimo de curiosear, por entretenimiento" (44); en otro momento, nombra el "museo de Grevin" y explica: "Boulevard Montmartre, figuras de cera" (38). En cambio, en los capítulos de la novela, hay anotaciones que orientan a aquel que no está familiarizado con el registro chileno. Anota, por ejemplo, "Bola de plomo ó [sic] hierro forrado en cuero y con agarradero para herir sordamente" para definir la palabra "laque"; en otro caso, explica que los "chocos" son "Carabinas recortadas para ocultarlas bajo la manta" (8). 
y el camino a seguir si se quiere revertir esa situación. En ese sentido, las escenas de El roto ofrecidas aquí al público son una propuesta estética para el porvenir, una imagen de lo que las letras americanas necesitan. La cuna..., en suma, es una primera sistematización del autor de lo que Bourdieu llama proyecto creador: "el sitio donde se entremezclan y a veces entran en contradicción la necesidad intrínseca de la obra que necesita proseguirse, mejorarse, terminarse, y las restricciones sociales que orientan la obra desde fuera" (Campo de poder... 19).

Un proyecto curioso, complejo y contradictorio que se verá puesto a prueba y resignificado cuando, por circunstancias derivadas de la Primera Guerra Mundial, Edwards Bello deba moverse desde París a Madrid, donde tomará contacto con los movimientos de vanguardia poética del momento y escribirá para sus principales revistas.

\section{Conclusiones}

Queda en evidencia que si bien Edwards Bello constantemente intenta zaherir a su clase social, es determinante para la aparición de sus primeras obras el estatus que le da pertenecer a una familia de la clase alta de su época: el primer periódico financiado por la madre; el conocimiento del amigo aristócrata que le permitió publicar El inútil; la posición de acomodo que sobrevino después de que lo "descubrieran" en Río y que le permitió ser testigo privilegiado de los efectos de la revolta; y, finalmente, el viaje y subsistencia en París que terminó con la primera publicación de una de sus obras en el viejo continente. Es por ello que el concepto bourdieano de escritor burgués desviado resulta tan apropiado a la luz de la reconstrucción que se ha llevado a cabo:

Es necesario ser burgueses, disponer pues de las reservas necesarias para poder resistir a las incitaciones directas de la demanda y esperar las remuneraciones materiales simbólicas necesariamente diferidas (a menudo hasta los últimos años de vida y aun más) que el mercado de los bienes simbólicos puede ofrecer a los artistas que no aceptan plegarse a las exigencias inmediatas del público burgués ... No es casual que los pintores y los escritores más innovadores del siglo XIX provengan en su mayoría de las clases privilegiadas: probablemente sus familias y ellos mismos eran más aptos 
y estaban mejor dispuestos a afrontar la inversión riesgosa y a largo término propia de quien emprende una carrera de artista. (Campo de poder... 117)

Ha quedado en evidencia, por otro lado, que en su construcción autobiográfica Edwards Bello hace el ejercicio de (sobre)interpretar cada una de sus primeras apuestas en el campo cultural como muestra temprana del potencial del "genio creador" que llegó a ser después. En estas páginas, se ha expuesto que esta claridad y decisión respecto del oficio de escritor no fue tomando forma sino hasta el momento en que quedó desprotegido, desnudo en un contexto hostil. Si hay algo sobre lo que Edwards Bello vuelve una y otra vez, es el impacto que tuvo el contexto parisino a partir de 1914 en la forma de verse a sí mismo y a sus compatriotas. Gran parte de las reflexiones que hace el autor en cuanto a la presencia de los escritores "indomediterráneos" en el campo literario europeo en La cuna... proviene directamente de esas experiencias. Es un Edwards Bello que asume una posición periférica, mas desde una postura esperanzadora, pues insta a los autores latinoamericanos a escribir sobre y para su misma gente.

Tras la publicación de La cuna..., Edwards Bello se instaló en Madrid, donde se incorporará a los círculos vanguardistas españoles. Llama la atención, considerando lo expuesto hasta aquí, que al ingresar en dichos circuitos las teorías latinoamericanistas y su ars poética expuestas en La cuna... perderán relevancia o, quizás, asumirán otro género y estética: la poesía dadaísta. Este estudio plantea que en París se produjo el despertar de un Edwards Bello consciente de su proyecto creador, pero será en Madrid donde se producirá su consolidación, bajo la máscara autorial de Jacques Edwards, poeta dadaísta y ultraísta. Pero eso ya es materia de otro artículo.

\section{Referencias bibliográficas}

Alone. Pretérito Imperfecto: Memorias de un crítico literario. Santiago de Chile, Nascimento, 1976. Impreso.

Alvarado Cornejo, Marina. "Ni aristócratas, ni rebeldes, ni tristes ni contentos: Escritura y Revistas Literarias de Joaquín Edwards Bello, Teresa Wilms Montt y Vicente Huidobro". Literatura y Lingüística, no. 21, 2010, pp. 29-44. 
Revistas culturales y literarias chilenas de 1900 a 1920: legitimadoras del campo literario nacional. Santiago de Chile, Editorial Cuarto Propio, 2016. Impreso.

Balmaceda Bello, Andrés. Bajo el polvo de los años: Recuerdos de juventud 1907-1917 y otros testimonios. Santiago de Chile, RIL editores, 2000. Impreso.

Benadava, Salvador. Faltaban solo unas horas... Aproximación a Joaquín Edwards Bello. Santiago de Chile, LOM Ediciones, 2006. Impreso.

Bourdieu, Pierre. Campo de poder. Campo intelectual. Buenos Aires, Editorial Montressor, 2002. Impreso.

Las reglas del arte: Génesis y estructura del campo literario. Barcelona, Editorial Anagrama, 2002. Impreso.

Carvajal, Osvaldo. "El pájaro verde' de Joaquín Edwards Bello: de crónica a capítulo de novela". Edwards Bello, Joaquín. El roto. Edición crítica. Santiago de Chile, Ediciones Universidad Alberto Hurtado, 2019, pp. 383-406. Impreso.

"La crónica modernista centroamericana y sus posibilidades editoriales: tres obras que merecen una edición crítica". Ístmica, Revista de la Facultad de Filosofía y Letras de la Universidad Nacional de Costa Rica, no. 20, 2017, pp. 11-25.

Dongui, Tulio Halperín. Historia contemporánea de América latina. Buenos Aires, Alianza Editorial, 1999. Impreso.

Edwards Bello, Joaquín. Crónicas. Valparaíso-Madrid. Santiago de Chile, Talleres gráficos “La Nación”, 1924. Impreso.

Epistolario sentimental. Santiago de Chile, Nascimento, 1969. Impreso.

La cuna de Esmeraldo. Observaciones y orientaciones americanas. Preludio de una novela chilena. París, Librairie Rosier, 1918. Impreso.

Memorias. Santiago de Chile, Leo Ediciones, 1983. Impreso.

Recuerdos de un cuarto de siglo. Santiago de Chile, Zig-Zag, 1966. Impreso.

. Tres meses en Río de Janeiro. Santiago de Chile, Aguilar Chilena de Ediciones, 2004. Impreso.

“Una idea". Diario de Alicante. 19 ago. 1909: 01. Impreso. 
. "Una idea”. La región Extremeña: Diario republicano. 23 ago. 1909: 01. Impreso.

. "Dos palabras". La Juventud. 17 mar. 1901: 01. Impreso.

Fischer Hubert, Denise. "El libro español en París a comienzos del siglo XX. Escritores i traductores". Tesis doctoral. Universitat Rovira y Virgili, 1994.

García-Huidobro, Cecilia. Un transatlántico varado en Santiago. Santiago de Chile, El Mercurio/Aguilar, 2005. Impreso.

Ramos, Julio. Desencuentros de la modernidad en América Latina: Literatura y política en el siglo XIX. México, D. F., Fondo de Cultura Económica, 1989. Impreso.

Subercaseux, Bernardo. Historia de las ideas y de la cultura en Chile: Desde la independencia hasta el Bicentenario (Volumen II). Santiago de Chile, Editorial Universitaria, 2011. Impreso.

Vicuña, Manuel. La belle époque chilena: Alta sociedad y mujeres de elite en el cambio de siglo. Santiago de Chile, Editorial Sudamericana, 2001. Impreso. 